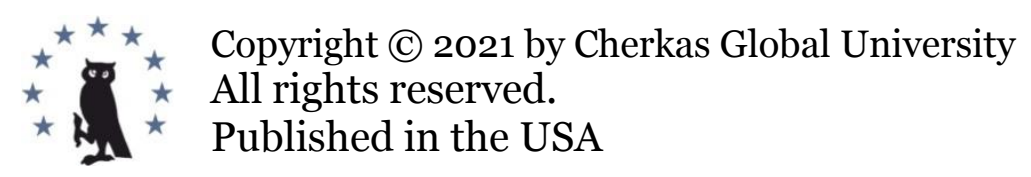

European Journal of Contemporary Education

E-ISSN 2305-6746

2021. 10(4): 879-887

DOI: $10.13187 /$ ejced.2021.4.879

https://ejce.cherkasgu.press

IMPORTANT NOTICE! Any copying, reproduction, distribution, republication (in whole or in part), or otherwise commercial use of this work in violation of the author(s) rights will be prosecuted in accordance with international law. The use of hyperlinks to the work will not be considered copyright infringement.

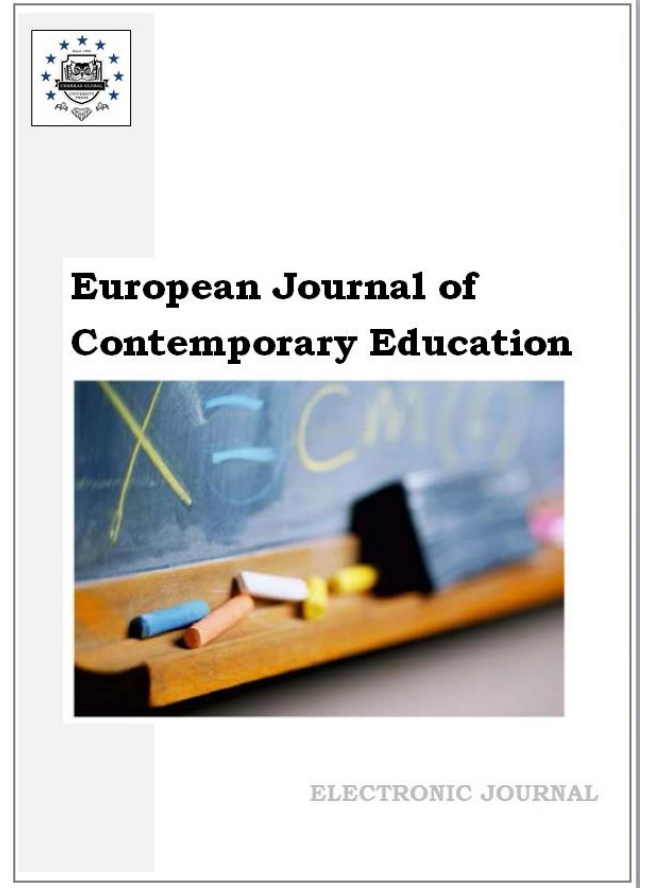

\title{
Adaptation of Students from Far Abroad and Neighboring Countries at South-Russian Universities
}

Tamara Chernikova ${ }^{a},{ }^{*}$, Eduard Sokalskiy ${ }^{b}$, Valentina Boluchevskaya ${ }^{c}$, Olga Shutova ${ }^{c}$

a Volgograd State Socio-Pedagogical University, Russian Federation

b Kalmyk State University named after B.B. Gorodovikov, Russian Federation

c Volgograd State Medical University, Russian Federation

\begin{abstract}
The problem of successful adaptation of foreign students is considered from the perspective of strengthening the international status of not only Russian education, but also the government as a whole. Two sides of the adaptation - psychological (generalized) and socio-cultural (expressed) were studied on 397 foreign students from southern Russian universities using diagnostic tools designed on A.L. Sventsitsky "Self-assessment of psychological adaptability", and the scales "Cultural commitment to the country" and "Social commitment to the country" from S.V. Frolova' questionnaire. Spearman's rank correlation coefficient was used for statistical data processing. Psychological and socio-cultural adaptation were considered in the relation "isolation identification" (V.I. Slobodchikov) and found a correlation $\rho<0.01$. According to the results, students from far abroad showed impoverished psychological adaptability with high demands for the success of socio-cultural adaptation. Assistance in its achievement from university teachers will occur when they will combine academic work with solving problems of educational and professional as well as social and communicative content. Students from the neighboring countries demonstrated an interconnected set of claims for successful socio-cultural adaptation, focusing on social ties and moving away from cultural ones. In this regard, the work of teachers is required to ensure the positive dynamics of intercultural relations with the involvement of the traditions of interethnic good-neighborliness in the territory of the southern region of Russia. Professional development programs for teaching staff should take into account the difference in cultural distance, manifested through the difficulties of a linguistic, cooperative, national, confessional nature.

\footnotetext{
* Corresponding author

E-mail addresses: tamara@vspu.ru (T.V. Chernikova), sokalskieduard@mail.ru (E.A. Sokalskiy), boluchevskaya@yandex.ru (V.V.Boluchevskaya), shoi1984@mail.ru (O.I. Shutova)
} 
Keywords: foreign students, psychological adaptability, socio-cultural adaptation.

\section{Introduction}

The issues of psychological and socio-cultural adaptation of foreign students obtaining education in the universities of Russia are associated with a broader range of problems. In contrast to the emphasis on socio-cultural differences, which mask the economic competition and political pretensions of countries, the problem of successful adaptation of foreign students is considered in the context of the tasks of strengthening international ties in education and public policy in general. Young people from abroad who have received education in Russia constitute an outpost in the stabilization of relations between countries. What is demanded of international students is a willingness to accept a different lifestyle and culture with its values. The hosting country is expected to be capable of empathic participation in activating and strengthening adaptive resources through overcoming language barriers (Latypov et al., 2017). In this regard, the tasks of contributing to the processes of adaptation of foreign students become on a par with the quality of their academic training. In the Southern Russian region, these processes are complicated by the multicultural circumstances of the educational environment and everyday life. In this regard, it is necessary to study the peculiarities of psychological and socio-cultural adaptation of students from far and near abroad in order to implement a differentiated approach in teaching, precisely responding to the needs of the foreign contingent in psychological and pedagogical support.

The research sample is comprised of 397 foreign students attending classes in three universities in southern Russia: Kalmyk State University (Elista), Volgograd State Medical University, and Adyghe State University (Maikop). The quantitative ratio of men (247) to women (150) in the total sample is 5:3. The central issue of the study is a focus on the actually existing contingent of students from far (110 people) and near (287 people) abroad without balancing the sample by gender and geographical origin of the entrants. Mathematical and statistical tools provide an opportunity to identify the differences that have become the basis for determining the strategies of targeted teaching to promote the adaptation of students from far and near abroad studying natural sciences $(62.47 \%$ of the total sample - future doctors, chemists, biologists, pharmacists), exact sciences (27.96 \% - future mathematicians, physicists and specialists in information systems, engineering, economics), and humanities ( $9.57 \%$ - future teachers and psychologists, philologists, journalists, lawyers, workers in the field of international relations).

\section{Materials and methods}

The goal of the conducted study is to determine the specific features of the relationship between the psychological adaptability and socio-cultural adaptation of students from far and near abroad in order to specify the objectives of the educational work of teachers and their re-training accounting for differences in the composition of international students.

The terms "adaptability" and "adaptation" describe two aspects of the same phenomenon, which are embedded in the two parts of the diagnostic toolkit. The first part, a variation of A.L. Sventsitsky's "Self-assessment of psychological adaptability" method adapted by us (Fetiskin et al., 2014: 466-467), is addressed to the constitutionally conditioned internal psychological resources of subject activity and communication (pace, flexibility, switchability, propensity for new contacts and impressions, etc.) studied in detail by V.M. Rusalov and colleagues. Out of the fifteen statements of the original version, which are to be agreed or disagreed with, ten affirmatively worded ones are selected. For the purpose of scoring, we divide them into two conditional subgroups characterizing "active adaptivity" and "communicative adaptivity". Cumulative adaptability is viewed in this method as a generalized attribute characterizing the potential for success of the external process of entry into a new cultural and social environment.

The second part of the diagnostic toolkit focuses on assessing the expression of the attribute, its external manifestation. The content of the scales "Cultural commitment to the country" and "Social commitment to the country" of the "Commitment to the country" questionnaire proposed in S.V. Frolova's doctoral thesis (Frolova, 2020: 472-480) is analyzed from the point of two groups of indicators of socio-cultural adaptation. The first group of indicators to a greater extent reflected the cultural interest in the country of study, conditionally labeled by us as the "need-pragmatic" character of adaptation. This group combines five indicators of the realization of personal interests 
through the receipt of an educational service. The indicators assessed on a ten-point scale are: 1 - intention to continue professional education in Russia; 2 - attitude to learning the Russian language; 3 - showing a great interest in anything in Russia that is significantly different from the culture of the native country; 4 - being sympathetic to the morals, habits, and lifestyle of representatives of Russian culture; 5 - admiring for the masterpieces of national culture and art in Russia. The second group of indicators to a greater extent reflects the social character of adaptation, conditionally referred to by us as the "identification-consolidating". Assessment of the five subsequent indicators conveys the degree of acceptance of the new social environment with the possibility of organic transition into it: 6 - analysis of the probability of living in the country of study; 7 - acquaintance with the experience of successfully settling fellow countrymen in Russia; 8 - taking care about expanding contacts in Russia; 9 - intention to move to Russia; 10 - entering the everyday way of life in Russia.

The self-assessment nature of diagnostics with the inevitability of obtaining subjective results in this study is reasonable and even desirable. It is the possibility of satisfying subjective interests and preferences in the conditions of receiving education in a foreign country that will be a reflection of the successful process of adaptation.

To determine statistically significant relationships between diagnostic indicators, we use Spearman's rank correlation coefficient $\mathrm{r}_{\mathrm{s}}$. Its use allows determining the significance of the correlation between the main pair of attributes - adaptability as a personal characteristic (generalized prerequisite) of socio-cultural adaptation and its actual implementation - and the private manifestations across the entire spectrum of indicators.

\section{Discussion}

Excluding participation in the discussion regarding the content of the concept of "adaptation," V.I. Slobodchikov's idea of the correlation of the processes of isolation and identification, which essentially reflect two sides of adaptation, is taken as the underlying theoretical idea. On the one hand, we take into consideration the issues of the strengthening and development of the basic psychological foundations, on the other hand - the identification characteristics of the establishment of external social connections and relations in the course of identification of oneself with the cultural environment. Asserting that "the structure of any human association can be described through the concepts of connections and relations," V.I. Slobodchikov defines "the driving force of the process of development of objective reality in a co-creative community"; according to the author, it consists of processes of isolation-identification (Antropologicheskii podkhod..., 2019: 17). V.I. Slobodchikov describes his formula as follows: "The unity and opposition of isolation and identification is precisely the constantly acting, living contradiction of co-existence that sets and directs the entire course of formation and development of human subjectivity and presents the general mechanism of this development. The development of new means in one process becomes a prerequisite for the unfolding of the other".

The subdivision of the process of adaptation into internal and external is also relevant for modern foreign studies. The list of internal predictors of learning adaptation includes communicativeness, activity motivation, self-efficacy, and value orientations. External factors of adaptation include the cultural distance between the home and host sides, as well as demographic characteristics, domestic circumstances, and differences in climatic conditions. It is especially noted that in foreign countries, much attention is paid to the issues of social support of foreign students - informational, emotional, and instrumental (Apasova et al., 2020).

The studied features of adaptation of students from far and near abroad serve as a basis for the formulation of answers to the research questions:

1. How does the difference between the indicators of psychological adaptability and sociocultural adaptation differentiate the strategies, content, and forms of educational work of teachers with foreign students from near and far abroad?

2. What issues are to become central in the development and implementation of professional development programs for university teachers working with students from near and far abroad? 


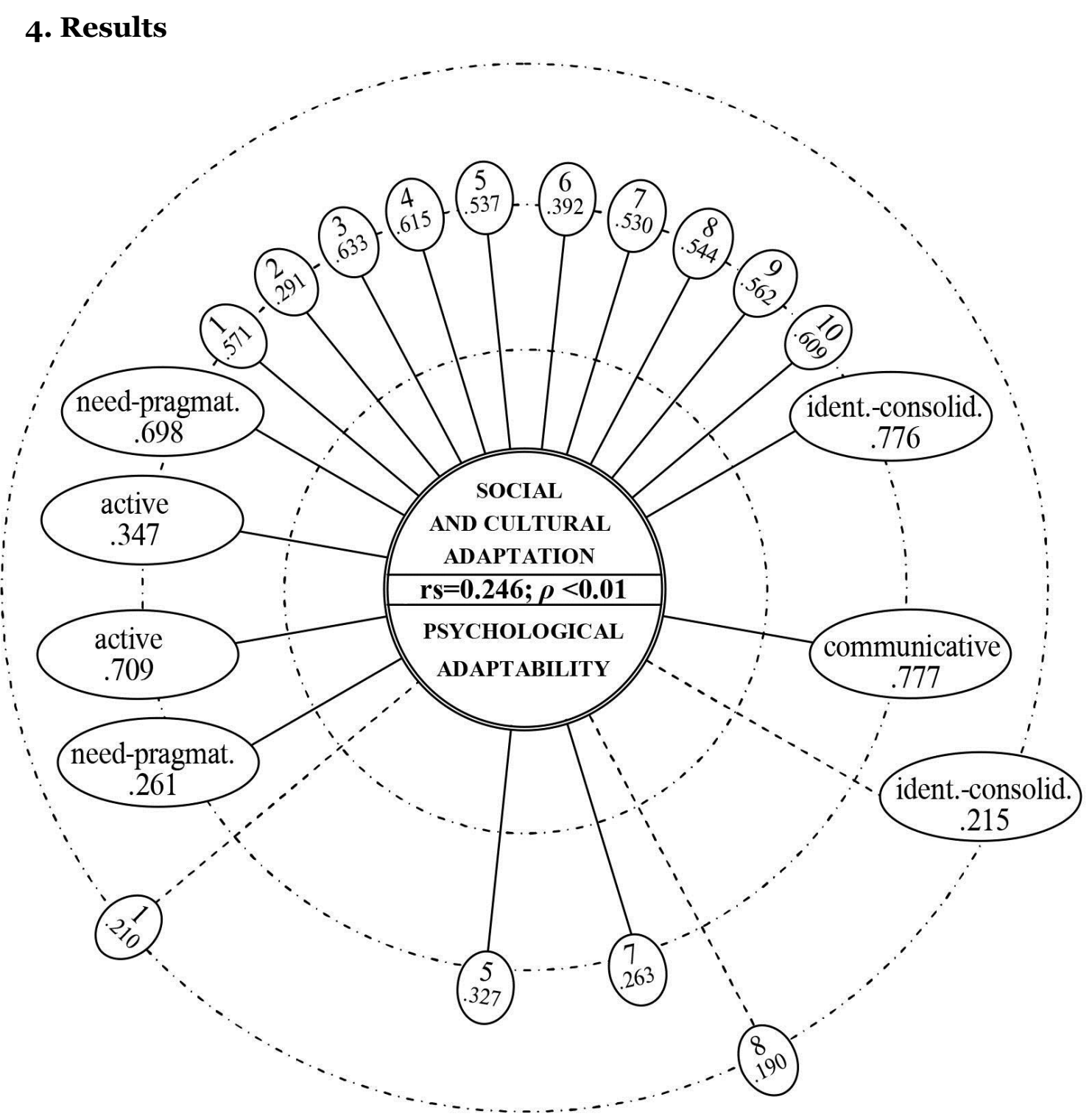

Fig. 1. Graphic representation of correlations between indicators of psychological adaptability and social and cultural adaptation among students from the far abroad

Symbols:

need-pragmat. - the need-pragmatic character of social and cultural adaptation; ident.consolid. - identification-consolidating character of socio-cultural adaptation; 1 - intention to continue professional education abroad; 2 - attitude to learning the language of another country; 3 - showing a great interest in anything in another country that is significantly different from the culture of native country; 4 - being sympathetic to the morals, habits and lifestyle of representatives of another culture; 5 - admiring for the masterpieces of national culture and art in another country; 6 - assumption sometimes of how life would be in another country; 7 - acquaintance with the experience of successfully settling fellow countrymen in another country; 8 - taking care about expanding contacts in another country; 9 - intention to move to another country as an opportunity to get closer to people who are very significant; 10 - awareness the close ties to the traditions of another country where one would like to continue his life 


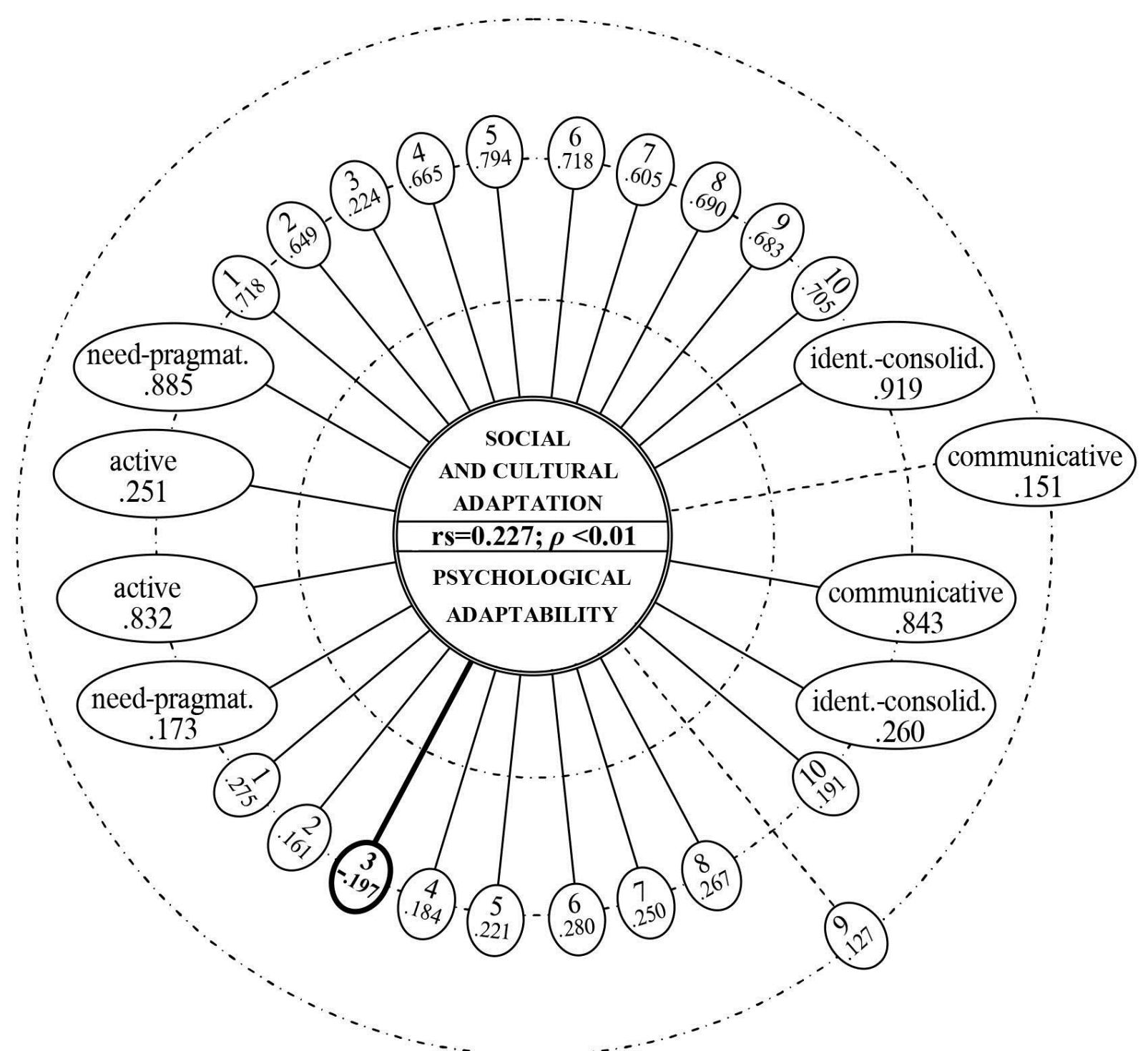

Fig. 2. Graphic representation of correlations between indicators of psychological adaptability and social and cultural adaptation among students from neighboring countries

Symbols:

need-pragmat. - the need-pragmatic character of social and cultural adaptation; ident.consolid. - identification-consolidating character of socio-cultural adaptation; 1- intention to continue professional education abroad; 2 - attitude to learning the language of another country; 3 - showing a great interest in anything in another country that is significantly different from the culture of native country; 4 - being sympathetic to the morals, habits and lifestyle of representatives of another culture; 5 - admiring for the masterpieces of national culture and art in another country; 6 - assumption sometimes of how life would be in another country; 7 - acquaintance with the experience of successfully settling fellow countrymen in another country; 8 - taking care about expanding contacts in another country; 9 - intention to move to another country as an opportunity to get closer to people who are very significant; 10 - awareness the close ties to the traditions of another country where one would like to continue his life.

Statistically significant links between the diagnostic indicators are detected by means of Spearman's rank correlation coefficient $r_{s}$ (Sidorenko, 2010). The use of this coefficient gives the opportunity to determine the significance of the correlation between the pairs of attributes. Data processing is conducted using IBM SPSS Statistics 26.0 software.

It needs to be stated that the diagnostic results reveal correlations of approximately equal strength between the general indicators of psychological adaptability and socio-cultural adaptation in students from far $\left(r_{s}=0.246 ; \rho<0.01\right)$ and near abroad $\left(r_{s}=0.227 ; \rho<0.01\right)$. Not very high 
correlation values reflect the differentiated content of the different sides of the adaptation process in foreign students. It should be noted straight away that no correlation of the maximum high level of significance is found for any of the pairs of the studied attributes $(\rho<0.001)$.

The results of express-diagnostics of the specific features of adaptation in students from far abroad. The study sample of students from far abroad includes 110 students, 76 men and 34 women, admitted from 18 countries in Asia and Africa. The majority of the students come from India (31.81 \%), Egypt (30.92 \%), China (6.36 \%), Jordan (5.45\%), and the United States.

The general indicator of psychological adaptability is directly associated with its active $\left(\mathrm{r}_{\mathrm{s}}=0.709 ; \rho<0.01\right)$ and communicative content $\left(\mathrm{r}_{\mathrm{s}}=0.777 ; \rho<0.01\right)$. Quite logical is the high significance of the correlation between the general indicator of socio-cultural adaptation and its constituent components - the need-pragmatic $\left(\mathrm{r}_{\mathrm{s}}=0.698 ; \rho<0.01\right)$ and the identificationconsolidating $\left(\mathrm{r}_{\mathrm{s}}=0.776 ; \rho<0.01\right)$. These connections are three times higher than similar indicators in the statistical results of psychological adaptability when identifying their associations with the components of socio-cultural adaptation: respectively, $r_{s}=0.261 ; \rho<0.01$ and $r_{s}=0.215$; $\rho<0.05$. On the part of the general indicator of socio-cultural adaptation, the connection with the active content of psychological adaptability is significant, although two times weaker than on the part of its general indicator $\left(\mathrm{r}_{\mathrm{s}}=0.347 ; \rho<0.01\right)$, while no correlation is detected with the communicative component $\left(\mathrm{r}_{\mathrm{s}}=0.074\right)$.

Psychological adaptability of students from far abroad is found to be substantively related to moderate interest in Russian national culture and art $\left(\mathrm{r}_{\mathrm{s}}=0.327 ; \rho<0.01\right)$, as well as in the experience of fellow countrymen who have settled down in Russia $\left(\mathrm{r}_{\mathrm{s}}=0.263 ; \rho<0.01\right)$. At the same time, psychological adaptability to new conditions has an even more moderate relationship to the motivation to continue education $\left(\mathrm{r}_{\mathrm{s}}=0.210 ; \rho<0.05\right)$ and actively expanding one's contacts in Russia $\left(r_{s}=0.190 ; \rho<0.05\right)$. As for the analysis of the probability of living in the country of study, there is a negative correlation with the overall index of psychological adaptability, although statistically insignificant $\left(\mathrm{r}_{\mathrm{s}}=-0.141\right)$.

The general indicator of socio-cultural adaptation of students from far abroad correlates significantly at the level of $\rho<0.01$ with all its aspects and individual manifestations. There are, however, quantitative differences in the degree of this correlation. Specifically, the leading correlations are those with the indicators characterizing the position of students from far-abroad countries as "tourist": interest in the distinctive characteristics of another country $\left(r_{s}=0.633\right)$, positive perception of the morals, habits, lifestyle of the representatives of the other culture $\left(\mathrm{r}_{\mathrm{s}}=0.615\right)$, understanding and acceptance of the traditions of another country $\left(\mathrm{r}_{\mathrm{s}}=0.609\right)$. The second line in decreasing order significance of the correlation is formed by characteristics of mastering a new educational and life environment: positive attitude to the fact of studying in Russia and the prospect of its continuation $\left(r_{s}=0.571\right)$, intention to move to another country as an opportunity to get closer to people who are very significant $\left(r_{s}=0.562\right)$, taking care about expanding contacts in the country of education $\left(r_{s}=0.544\right)$, admiration for the cultural heritage of the country $\left(\mathrm{r}_{\mathrm{s}}=0.537\right)$, acquaintance with countrymen who have successfully settled in Russia $\left(r_{s}=0.530\right)$. The third line of correlation links, the most insignificant, is formed by the results of the assessment of the probable prospects of living in Russia on a permanent basis $\left(r_{s}=0.392\right)$ and attitude to learning the Russian language $\left(\mathrm{r}_{\mathrm{s}}=0.291\right)$.

The visual representation of the correlations in Figure 1 reveals an imbalance in the resource provision of the general indicators of psychological adaptability and socio-cultural adaptation in students from far abroad. The interconnected resource of psychological adaptability is expressed weaker in comparison with the complex of socio-cultural connections. The basis of the psychological adaptive potential is constituted by low demands of the need-pragmatic character $\left(r_{s}=0.261\right)$, as well as weak relationships in the sphere of social communication with fellow countrymen in Russia $\left(r_{s}=0.263\right)$, as well as other people $\left(r_{s}=0.190\right)$. It can be assumed that psychological adaptability is more of a superficial-communicative nature, which is unlikely to provide a sufficient resource base for sociocultural adaptation in a foreign country.

Materials of a survey indicate that international students from Asian and African countries have themselves identified problem areas and suggested ways to strengthen their adaptive capacity (Chernikova, Boluchevskaya, 2020). First and foremost, the young people insist on studying together in groups with Russian students, viewing academic communication as a means of mastering the social space and expanding interpersonal and business relationships. At the same 
time, they feel the lack of extracurricular contacts of the additional-educational and recreational type with students and teachers (discussion platforms, festivals, excursions, etc.). A quarter of the requests to the faculty are for assistance in personal development and self-actualization, which is expressed in the need to get "creative and invested support through cooperation" to improve soft skills - critical thinking, creativity, business cooperation, evidentiary reasoning, predictive design.

Studies by V.A. Fedotova and S.Iu. Zhdanova conducted on groups of Indian and Arab respondents show that students from India most often feel the need for this kind of assistance (Fedotova, Zhdanova, 2020). For them, predicting situations is a significant difficulty, and therefore they seek social support. Arab students, in comparison, are more adapted to the learning process due to group involvement. Because of this, they are also more capable of making personalsituational predictions. By the example of studying the religious identity of Muslim students, O.S. Pavlova, V.M. Minazova, and O.E. Khukhlaev point out the significance of the relationship between religious parameters and social consolidation (Pavlova et al., 2016). The consequence of such a situation is probably the more favorable microenvironment of students in the group of compatriots from Egypt.

The correlations obtained on the sample of students from far abroad, which are clearly demonstrated in Figure 1, can be considered as an approximate basis for the selection and development of the content and methods of teaching. The limited psychological resources of adaptation and the expectation of high academic and sociocultural results set the organizers of higher education the task of intensifying the educational process by framing the learning and activity content in the forms that motivate the expansion of the social field of interaction. First and foremost, work will be needed to increase interest in learning Russian, for example, through creative assignments for spontaneous dialogic communication. The experience obtained will serve as an object of discussion in several directions simultaneously. First, the cultural differences and their underlying reasons will be identified, which will boost interest in the life of people in another country. Second, understanding the roots of unfamiliar phenomena will expand the field of communicative safety and ensure active mastery of the new social reality. Third, new opportunities will open up for establishing the relationships of cooperation with people in the country of study. The last point is the most vulnerable, judging by the lack of significant correlations with the issues of assessing the probable prospects of living in the country of study, moving there to people who are close in spirit and lead an attractive way of life. Thus, specially targeted work on strengthening psychological adaptability as a generalized attribute will strengthen the potential base for a holistic adaptation process. This will technologically provide for the main request from students from far abroad - about psychological and pedagogical support through the step-by-step accompaniment of their socio-cultural adaptation in the direction of identification and consolidation with new people in new life circumstances in another country.

The results of express-diagnostics of the specific features of adaptation in students from near abroad. The research sample of students from neighboring countries consists of 287 students, 171 men and 116 women. All of them come from former Soviet republics located primarily in Central Asia: Turkmenistan (86.40\%), Uzbekistan (6.97\%), Tajikistan (2.44 \%), and Kyrgyzstan (2.09\%).

The general indicator of psychological adaptability and the two of its aspects (active and communicative) in students from near-abroad countries has a similar pattern of correlations with the general indicator of socio-cultural adaptability and two of its components (the needpragmatic and the identification-consolidating) (Figure 2). Just as in the previous case, the general indicator of psychological adaptability has closer connections with the active component $\left(r_{s}=0.832 ; \rho<0.01\right)$ than the general indicator of socio-cultural adaptation $\left(r_{s}=0.251 ; \rho<0.01\right)$. The same applies to the connections of the general indicator of psychological adaptability with the communicative component $\left(\mathrm{r}_{\mathrm{s}}=0.843 ; \rho<0.01\right)$ in comparison with the degree of association with it of the general indicator of socio-cultural adaptation $\left(\mathrm{r}_{\mathrm{s}}=0.151 ; \rho<0.05\right)$. It is readily apparent that the opposite is also true: the correlations between the general indicator of socio-cultural adaptation and its two aspects are three to four times stronger than those of the general indicator of psychological adaptability: with the need-pragmatic $-\left(\mathrm{r}_{\mathrm{s}}=0.885 ; \rho<0.01\right)$ against $\left(\mathrm{r}_{\mathrm{s}}=0.173\right.$; $\rho<0.01)$ and with the identification-consolidating $-\left(\mathrm{r}_{\mathrm{s}}=0.919 ; \rho<0.01\right)$ against $\left(\mathrm{r}_{\mathrm{s}}=0.260\right.$; $\rho<0.01)$. 
At the same time, major differences are found already in the comparison of the quantity and strength of correlations between the general indicator of psychological adaptability and the characteristics of socio-cultural adaptation. First of all, correlations at the significance level of $\rho<0.01$ are found between the general indicator of psychological adaptability and all ten components of socio-cultural adaptation (from $r_{s}=0.280$ to $r_{s}=0.127$ ). Comparison of the images in Figure 1 and Figure 2 gives a clear idea of how impoverished the correlations of indicators in the sample of students from the far abroad look in comparison with the sample from the near abroad. Nevertheless, in this series of positive correlations, the respondents from neighboring countries have two phenomena that cannot help but be alarming. First, the most insignificant positive relationship is detected with the indicator reflecting weak intentions for cultural rapprochement with other people that are significant up to the point of moving into their territory $\left(r_{s}=0.127\right.$; $\rho<0.05)$. Second, a significant negative correlation shows the lack of interest in anything in Russia that is significantly different from the culture of the native country $\left(\mathrm{r}_{\mathrm{s}}=-0.197 ; \rho<-0.01\right)$. The latter fact is particularly troubling because only three decades ago, these states were union republics and represented, together with the Russian Federation, a single country.

The general indicator of socio-cultural adaptation of students from near abroad, same as in the previous sample, significantly correlates at the level of $\rho<0.01$ with all of its aspects and individual manifestations. Whereas in students from far abroad, these relationships quantitatively differ, in this case, they are, for the most part, consistently high and level (from $\mathrm{r}_{\mathrm{s}}=0.794$ tp $\mathrm{r}_{\mathrm{s}}=0.649$ ). An exception is the same indicator of relatively weak, compared to other relationships, association with the expression of interest to the characteristics of Russian culture that differ from the national culture of former Soviet republics in Central Asia. It turns out that even those natives of former Central Asian republics of the Soviet Union who speak the Russian language, are obtaining higher education in our country, and have favorable psychological conditions for adaptation tend to initiate and maintain some personal, social, and cultural distance with respect to the way of life in Russia.

This situation poses very specific challenges to the educational activities of the universities in the cities of Southern Russia accepting students from neighboring countries. A.R. Gapsalamov and co-authors note that the adaptation of foreign students to the social and educational environment of a small city is more challenging than in a big city, among other things, due to the level of professional training of the teachers competent in developing effective strategies for the integration of foreign students into the educational and socio-cultural environment (Gapsalamov et al., 2016). To maintain a positive dynamic of educational, interpersonal, and broad social relations, the educational situation created in universities has to be highly attractive. The subjectoccupational training, regardless of its special content, should provide sufficient opportunities to incorporate the achievements of Russian culture, science, and art, which are of global significance and have had a substantial impact on the development of the industrial and social sphere of other countries. This is particularly true for extracurricular work, the systemic nature of which will set the standards for national-cultural dialogue and commonwealth.

\section{Conclusion}

1. Comparison of the two samples of international students reveals a similar correlation relationship of average significance level between the general indicators of psychological adaptability and socio-cultural adaptation. The modest level of correlation is a testimony to the differentiated content of the internal (generalized) and external (expressed) sides of the process of adaptation. The results of a detailed analysis of the indicators of the relationship found in the samples of students from far and near abroad prescribe different teaching strategies. At the same time, the content of the programs of professional development for scientific and pedagogical workers will be different and should be designed taking into account the difference in the cultural distance caused by linguistic, national, and confessional barriers.

2. The limited resource range of psychological adaptability of students from far abroad paired with high aspirations for successful socio-cultural adaptation leads higher education organizers to support their personal development - creative communication and flexible thinking in learning activities. The tasks of combining academic content with the intensification of interpersonal and business communication in real circumstances of professional and broad social interaction are to be solved. In the context of additional education, it is necessary to activate the creative group 
productivity of teachers in the development of innovative personality developing technologies of educational work.

3. Given quite considerable resources of psychological adaptability and high pretensions of sociocultural adaptation, students from neighboring countries show a significant negative relationship with the expression of interest in the achievements of Russia and weak intention of communicating and getting closer to significant people in the country of their study. The objective of teachers in higher education when working with students from neighboring countries coming mostly from the former Central Asian republics of the Soviet Union is to ensure the positive dynamics of academic and extracurricular intercultural relations in an educational environment that is comfortable for representatives of different nationalities. In this way, the traditions of the multinational South of Russia will be activated and supported within the walls of the university, demonstrating a long-term experience of cultural good-neighborliness. Interactive forms of teachers' exchange of their experiences in the course of professional development will focus on gaining the experience of students' participation in the cultural life of Russia through various forms of academic work.

\section{References}

Antropologicheskii podkhod..., 2019 - Antropologicheskii podkhod v razvitii vospitaniya i sotsializatsii detei i molodezhi [Anthropological approach in the development of education and socialization of children and youth]. 2019. Ed. V.K. Ryabtsev. Moskva: FGBNU «IIDSV RAO». [in Russian]

Apasova et al., 2020 - Apasova, M.V., Kulagina, I.Yu., Apasova, E.V. (2020). Usloviya adaptatsii inostrannykh studentov $\mathrm{v}$ vuzakh [Conditions for the adaptation of foreign students to universities]. Sovremennaya zarubezhnaya psikhologiya. 9(4): 129-137. [in Russian]

Chernikova, Boluchevskaya, 2020 - Chernikova, T.V., Boluchevskaya, V.V. (2020). Adaptatsiya inostrannykh studentov v vuzakh Rossii i Kazakhstana: konstruirovanie i aprobatsiya programmy ekspress-diagnostiki. [Adaptation of foreign students in universities of Russia and Kazakhstan: design and testing of the express diagnostics program]. Teoreticheskie i prikladnye aspekty sovremennoy psikhologicheskoy nauki. Atyrau: Kh. Dosmukhamedov Atyrau University Publ. Pp. 96-102. [in Russian]

Fedotova, Zhdanova, 2020 - Fedotova, V.A., Zhdanova, S.Yu. (2020). Adaptatsiya studentov iz Indii i arabskikh stran $\mathrm{k}$ obrazovatel'nomu prostranstvu rossiiskikh vuzov [Adaptation of students from India and Arab countries to the educational space of Russian universities]. Sotsial'naya psikhologiya i obshchestvo. 11(2): 96-106. [in Russian]

Fetiskin et al., 2014 - Fetiskin, N.P., Kozlov, V.V., Manuilov, G.M. (2014). Sotsial'nopsikhologicheskaya diagnostika razvitiya lichnosti i malykh grupp [Socio-psychological diagnostics of the development of personality and small groups]. Saratov: Vuzovskoe obrazovanie. [in Russian]

Frolova, 2020 - Frolova, S.V. (2020). Sotsial'no-psikhologicheskaya kontseptsiya priverzhennosti lichnosti strane: Avtoref. diss. ... d-r psikhol. nauk [Socio-psychological concept of the individual's commitment to the country: dissertation of Ph.D of psychological sciences]: Saratov. [in Russian]

Gapsalamov et al., 2016 - Gapsalamov, A.R., Gallyamova, Z.V., Zakirova, O.V., Ibragimova, E.R., Tarasova, E.R., Tirigulova, R.Kh. (2016). Foreign students' adaptation to the social and educational environment of a small city as a condition of undergraduate. The European Proceedings of Social \& Behavioural Sciences: 2nd International Forum on Teacher Education. London: Future Academy. Pp. 404-410.

Latypov et al., 2017 - Latypov, Z., Ziyatdinov, A., Demidova, L., Gerasimov, V., Zaostrovtseva, $M$. (2017). The problem of adaptation of foreign students studying in Russian universities. Revista ESPACIOS. 38(56): 27-34.

Pavlova et al., 2016 - Pavlova, O.S, Minazova, V.M., Khukhlaev, O.E. (2016). Religious identity of Muslim students (based on the study of youth, living in the Chechen republic). CulturalHistorical Psychology. 12(4): 90-99.

Sidorenko, 2010 - Sidorenko, E.V. (2010). Metody matematicheskoi obrabotki v psikhologii [Methods of mathematical processing in psychology]. Sankt-Peterburg: Rech'. [in Russian] 